\title{
Field Work in the Elementary School
}

\section{Zonia Baber}

To cite this article: Zonia Baber (1905) Field Work in the Elementary School, Journal of Geography, 4:1, 18-22, DOI: 10.1080/00221340508985565

To link to this article: http://dx.doi.org/10.1080/00221340508985565

\section{Published online: 12 May 2008.}

Submit your article to this journal
Џlll Article views: 6

Q View related articles $\longleftarrow$

4 Citing articles: 2 View citing articles 


\title{
FIELD WORK IN THE ELEMENTARY SCHOOL *
}

\author{
BY ZONIA BABER \\ School of Education, University of Chicago, Chicago, III.
}

I

$T$ is a recognized law that an organism develops through satisfying its needs and that it assimilates only that which it requires for its growth. If, however, the proper stimulus is lacking, or reaction to the stimulus is inhibited, growth ceases and the organism becomes atrophied.

Since this law holds good in the realm of intellect as well as in that of the physical being, the knowledge of the reaction of the child's activities to natural and social stimuli would form the most valuable contribution to human acquirement, since it would enable education to take its place in a parliament with physics, chemistry and the other natural sciences.

However humiliating to the teaching force the fact may be, the statement remains undisputed, that the science of education, which is the greatest of all sciences since it deals with the human soul, has lagged far behind. the others in its development.

A few principles relating to the scientific process in education have been. discovered and formulated but they have not been the controlling factors in the warp and woof of the educational fabric. With the principle ringing in our ears-Mental activity is dependent upon self experience, we proceed to make schools which successfully inhibit the child's gaining new experiences, confining him to the experiences of others; after years of study of texts his. enthusiasm for learning may frequently be represented by an inverse ratio to. his scholastic experience.

When we contemplate the task the school formerly set itself, that of perpetuating book lore, we are not surprised when we read the sign, written in invisible letters, upon the façade of almost every school house, "A Refined Cramming Industry, Limited."

Knowledge has accumulated with such prodigious rapidity that the school now cries out in despair, "The task is Herculean, it is impossible!" Even if it were possible to stretch the elastic memory until it could retain all known facts the result would be deplorable. Although one may be able to repeat volumes of the world's richest knowledge, it has no meaning to the individual unless assimilated by self-experience. Character is not made by repeating what the wise and good have said, but by one's doing something wise and good on one's own account. After a few years of the cramming process the student becomes a slave to second-hand experiences. $\mathrm{He}$ is helpless when confronted by a new situation without the sustaining

\footnotetext{
* Read before Educational Section of Eighth International Geographic Congress.
} 
crutch of the text-book. The individual loses the power of initiative, independence, vigor and integrity of mental action. We are beginning to discover that we have made knowledge the end instead of the means of reaching our goal. To give the individual control of all of his powers, to bring him to a realization of his highest possibilities, should be the aim of the school, not the acquisition of facts. This can not be accomplished by the use of text-books alone.

Before our population was so largely urbanized, the child gained possession of his powers by first hand contact with nature and by participation in the industrial activities of the home. Now the school must assume the responsibility of the industrial training once given in the home. To this end our schools are slowly introducing cooking, sewing, weaving, work in wood, clay and metal, gardening and field work.

Contact with material furnished by nature engenders a certain mental activity which the mere observation of conditions fails to satisfy. This need we term a problem, and it is to the mind what appetite is to the body; it determines the food necessary for growth; it focuses the energy toward a definite end; it directs attention and observation for the collection of data, from nature, books, people and cultural products; it calls the imagination into play in forming hypotheses and, if properly utilized, tests the hypotheses by experiment, selecting relevant material, discarding the irrelevant until a conclusion is reached which bears the test of reason.

In organized mental activity the individual finds the highest pleasure. The student who is given opportunity for the exercise of all his powers from his entrance into school needs no price, per cent., nor degrees to stimulate him to action. The reward is in the joy of the doing.

It is only through the solution of the student's own problem that he gains true intellectual development. The power of imagination, reason, observation, memory, can not be developed except by the presentation of conditions which stimulate mental activity in connection with the mind's own normal movement. It is true that the mind may be trained to tricks of memory or observation, but it has been shown that this acrobatic mental skill does not go over into the intellectual power of the individual.

Field work offers an opportunity for such individual development. Every region is rich in problems for the student from the kindergarten age to the adult. Even the six year old has a problem when he makes an excursion to the farm to see how the farmer overcomes difficulties in tilling his crops and tending his stock. In his own little garden the seeds may be planted by hand, tilled with a hoe; but the farmer must devise other methods for his larger work. 
Excursion to the sea shore or lake shore, to a river, to sand dunes, to a mountain, volcano, swamp, to regions where glacial phenomena are illustrated, to caves, quarries or mines, will furnish physiographic problems for pupils above the fifth grade and bring the younger children in first hand contact with natural objects in their normal setting.

Few localities can boast of all these geographic examples, but many may be found within a radius of from fifteen to thirty miles from any school.

Many of the world's important industrial activities, such as farming, lumbering, grazing, fishing, mining, manufacturing, quarrying, building, trading, and others, may be seen within the same radius.

Through visits to the accessible industries the student gains an appreciation of the cultural products of the earth. Greater returns may be expected from a single visit to a certain industry if the students are engaged in the same activity at school or at home.

It is rare that a physiographic area is so simple that one visit may exhaust its possibilities. When changes are taking place with a noticeable rapidity, as at the seashore, in the river valley, or at the sand dunes, visits from year to year give the dynamic conception of the mobile crust of the earth.

Young children form definite images through many contacts with the same material, and they retain definite images but a comparatively short time. Hence they require many and frequent excursions.

Children younger than ten or eleven years of age are interested principally in collecting material -in the activity itself, rather than in causal relations, although the important aspect of cause is not excluded from their wide range of investigation of the wonders with which they find themselves surrounded. Interest in the relations of things can rarely be sustained for sufficient time to test an hypothesis. But after about the eleventh year the causal relation makes a stronger appeal to them and about the age of thirteen or fourteen the student shows much interest in pure abstract thinking.

Interest in physiographic processes may be manifest in a certain degree as a result of field work in any of the grades of the elementary school, yet it is in no sense a dominant factor until the upper grades are reached. Here interest in the problem will carry the student, through a series of experiments with running water, waves, air currents, and other forces, testing his hypothesis to ascertain the cause of observed phenomena and will also lead him to search books for farther data which may contribute to the solution.

The benefit of the excursion is not exclusively intellectual. It is useless perhaps to mention the physical advantage of exercise in open air since this 
is self-evident. But the social relation of teacher and pupil and of the pupils with each other is so normal and natural, free from the artificial conditions which per force of circumstances must obtain in even the most natural schools, that the teacher has an opportunity to reach the real child too often screened in the school room.

Admitting the desirability and necessity of changing the center of gravity of our school system from the slavish study of the text-book to a study of the environment, with all its activities, which requires for its understanding knowledge of other times and distant climes, the task at present is a difficult one. In the first place the change of standpoint is so recent that teachers, themselves reared for the most part on the text-book plan, are illy prepared for any other work. Where there is an attempt to carry out a new ideal, the community, always conservative, wishing to cling to traditions, frequently puts obstructions in the path of the aspiring teacher. This difficulty may be removed by educating the community through the children and through parents' meetings. The expense which is necessarily attendant upon field work is also a matter of grave consideration in most regions. We spend money readily upon the things for which we have a habit of spending, but hesitate when a new expense is incurred. When field work becomes customary either the parents or the school trustees will defray the expense, just as they do for every other feature of our school system which is considered essential.

Another difficulty results from the large numbers of children for which each teacher must under present conditions be responsible. The physical care of fifty children on an excursion is no small responsibility. An extra teacher is a necessity in each school building to aid the regular teacher on her excursions or to attend to half the students during her absence. With care accidents are rare. In sixteen years' experience in the field with many hundreds of children I have never known of a single accident during an excursion. Large classes are not desirable in field work, nor in the class room, yet they are not prohibitive. The individual must suffer in collective treatment in the field as well as in the school room. But the field with its numerous aspects gives opportunity for satisfying interests of each individual which the school room frequently denies. . The interest manifested by a class in the discussion of a field trip leaves little doubt of the superior vitality of knowledge gained from self-experience compared with secondhanded information.

The organization of the elementary school in this country is far more favorable to making field excursions an integral part of its work than is that of the high school. The departmental teaching in the secondary school makes it 
next to impossible with the attitude of the teachers of the special subjects to have excursions except after school hours or on Saturdays. This puts the field work at a disadvantage, but in the elementary school the teacher is mistress of the situation. Although Pestalozzi introduced field work into his geography teaching at Yverdon, Switzerland, a hundred years ago, the schools of this country have been slow in realizing its value-in recognizing that it is fundamental to all true geography teaching.

\section{DISTRIBUTION OF THE CINCHONA TREE}

Mr. J. Dronke, in his monograph on the transplanting of this plant from its native home in South America to Asia, gives some interesting facts concerning its present distribution. The habitat of the cinchona is between $10^{\circ}$ North and $22^{\circ}$ South latitude in the Andes and among the coastal mountains of Venezuela and Colombia. The upper limits of its range are, according to the species of the tree, from 800 to 3,000 metres. The first attempt to transplant it was in 1850, when it was taken to Algeria, with poor success. In 1854, Mr. Hasskarl, for the Dutch government, introduced young trees and seeds into Western Java. It was found to thrive finely in well-watered regions between 1,500 and 1,700 metres above the sea, and with an average temperature of about $17^{\circ}\left(62^{\circ} \mathrm{Fahr}\right.$.). When it was discovered that $\mathrm{Cin}$ chona Calisave var. Ledgeriana supplied the most valuable medicinal product the cultivation was confined to this species.

The cinchona industry rapidly developed in Java, and that island now far surpasses all other lands in the quantity of quinine produced. Eighty per cent. of the world's product comes from Java, and the plantations cover 20,000 acres. The tree was introduced into Southern India in I86I; but though it thrives there it has in recent years been neglected, on account of the decreased price of cinchona bark, so that in I 899 the plantations covered only about 5,000 acres. It was taken into Northern India along the southern slopes of the Himalayas, and in Sikkim, but its cultivation there has not been important. The production of cinchona bark in Ceylon steadily grew for twenty years after its introduction in $\mathrm{I} 86 \mathrm{I}$. In $\mathrm{I} 88 \mathrm{I}$ the island was one of the greatest sources of supply. In the following ten years, however, the production greatly declined, and fell from over 15,000,000 to 510,462 pounds. Other attempts to introduce the plant into Asia, Africa and Australia have not met with success.-Bull. Am. Geog. Soc., November, 1904 . 